\title{
The method of anti-risk management of agro-industrial complex projects based on the critical path
}

\author{
K. J. Krol \\ University "KROK”, Kyiv, Ukraine \\ Corresponding author. E-mail: krolkonrad6@gmail.com
}

Paper received 18.06.21; Accepted for publication 11.07.21.

\section{https://doi.org/10.31174/SEND-NT2021-255IX32-10}

\begin{abstract}
The article presents the method of anti-risk management of agro-industrial complex projects based on the critical path, as well as the algorithm of anti-risk management method of agro-industrial complex projects based on the critical path was developed, which allows when constructing the network schedule of the project to consider not only the duration of works, but also the value of risk of the project of agro-industrial complex. The application of this method will help the project manager to manage project risks more effectively and, as a result, to improve the quality and quantitative indicators of agricultural production.
\end{abstract}

Keywords: projects, risk management, method, risk management methods, agro-industrial projects.

Introduction. Project stakeholder management is an important component of project management. The stakeholders of the projects of agro-industrial complex have their own specifics. Risks associated with project stakeholders can be devastating for the projects. And given the social role of agrarian projects, the collapse of such projects is unacceptable. The products of agrarian projects are the products of livestock and crop production in natural or processed form. Ukraine is one of the key suppliers of crop products to the world agricultural markets. Livestock products of domestic producers are just beginning to be recognized in the markets of the European Union. The introduction of project management in the domestic agroindustrial complex will help agricultural producers to improve the quality and volume of crop and livestock products, as well as will help to meet the demand of domestic consumers and increase imports of agricultural products. It should be noted that global trends in the consumption of organic products and compliance with requirements to reduce negative impact on the environment in the production of products, contributes to the revision of state regulation of agricultural production rules by domestic producers. Despite the fact that consumers and government agencies are stakeholders in agricultural projects, it is necessary to consider their interests when implementing such projects. But the implementation of these requirements requires changes in the process of usual production for farmers, bears, in addition to the additional costs, also the resistance to changes of employees of agricultural enterprises, who are also the stakeholders of agro-industrial projects. When managing project stakeholders, the project team encounters the need to resolve misunderstandings and conflicts that arise during such project implementation. That is why the qualitative identification of all project stakeholders, definition of their mentality, interests, expectations and requirements from the project implementation, as well as the assessment of their influence on the project and assessment of risks related to the project stakeholders is an important element of the project stakeholder management planning phase. During the planning phase of the project, it is advisable to calculate the option of planning full paths of works, so that the priority criterion for determining the critical path is not the time of the project, but the minimum risk. Such planning in agrarian projects has significant advantages in that the collapse of the project, due to the occurrence of the risk situation related to the stakeholders of the project, can lead to the closure of the project, unacceptable in view of social effect of agrarian projects. To solve this issue, the author proposes the method of anti-risk management of agro-industrial complex projects based on the critical path. This method takes into account the specifics of the subject area and is a practical tool that can be applied to projects in all sectors of agriculture.

Analysis of latest researches and publications. Fundamentals of the theory of stakeholders were laid by R.E. Freeman in the work [1], where the author defined the concept of stakeholders. R.E. Freeman proposed hypothesis, which was that the organization and its environment can be represented as a set of stakeholders in its activities, the interests and requirements of which should be taken into account by managers [2].

T. Donaldson and L.E. Preston in work [3] have defined the theory of stakeholders, as a management approach, which recommends use of methods and practice that make a philosophy of stakeholder management. This philosophy aims to describe, understand, analyze and manage stakeholders and provides a framework for analyzing the behavioral aspects of stakeholder management.

When managing the stakeholders of projects, it should be taken into account that the success of the project depends on all stakeholders [4]. R. Sisodia, D. Wolfe, J. N. Sheth [5] noted that none of the stakeholder groups can be regarded as the main one. R. Mitchell, B. Agle and D. Wood [6] insisted that it is necessary to manage all stakeholders, even those who do not directly interact with the organization. The stakeholders of the project should be considered as a single structure, where all the elements are linked by common interests.

In the work [7], project relationships are defined as relationships between all project stakeholders in different contexts. Time is a defining feature of the relationship - both past and future influence current behavior in such relationship. In addition, interactions underlie stakeholder experiences and expectations. Each relationship is unique in its content, dynamics, and impact on the parties involved. So, it is not just a question of whether stakeholders and projects are connected, but also how effectively they are connected [8].

The stakeholder management of projects affects the effectiveness of project implementation. C. Scott-Young, D. Samson in the work [9] noted the importance of stakeholder management to achieve project goals. To do this, project 
activities should pay more attention to the needs and expectations of project stakeholders [10]. This idea is supported by scholars in the work [11], which noted that all responsibilities and roles, during the implementation of the project should be considered as a response to the expectations of project stakeholders. To begin with, in the planning phase of project stakeholder management, the project team identifies stakeholder expectations of the project, then considering the project objectives, discovers the possibility of matching the future project product with stakeholder expectations. During the course of the project, the stakeholder's expectations are checked and, if necessary, communications are made to adjust stakeholder expectations. It is because if stakeholder expectations are not met, the success of the project will not be fully achieved. For example, inflated expectations can lead to stakeholder disappointment with the results of relevant project.

Orlander and Landin [12] noted that communication with stakeholders should be open, reliable, and informative. Trust, integrity, and ethics are the foundation of good relationships between project stakeholders.

O. Verenych in the work [13] noted that the organization of interaction between the stakeholders and communication are the most important competencies of project manager. The reason for the lack of interaction and communication can be a lack of integrated understanding of all project processes by all participants.

In addition to expectations, the interests of each stakeholder shall also be identified. Frank Harris [14] noted that the various interests of stakeholders should be recognized by the project team and subject to constant review. In the work [15] it is noted that incomplete and untimely consideration of the interests of project stakeholders can lead to unexpected issues and uncertainty in the projects. The power / interest model $[11,7]$ is used to determine stakeholder expectations and interests and is widely used to analyze the influence of stakeholders in the project.

Y.Y. Husieva [16] noted that the project should provide only those functions, features or technical characteristics that are necessary to meet the requirements of its stakeholders, using only those resources for which the customer or investor is willing to pay.

Ineffective stakeholder management leads to project delays and cost overruns [11]. This statement also applies to the agricultural projects. Scientific studies performed by scholars $[17,18,19]$, noted the need for a structural approach to the identification, prioritization and involvement of the stakeholders. It is noted that the success or failure of the entire project depends on the ability of project team to identify correctly and manage effectively all stakeholders of the project [20].

Project management standards reflect the stakeholder management processes. The most common are the following: PMBOK PMI [20], P2M [21], ICB IPMA [22], ISO 21500 [23].

For stakeholder management such models are used as: Mitchell's model of stakeholder significance identification, in which each stakeholder is analyzed according to the following indicators: power, legitimacy and urgency of demands [2, 6, 24]; balance model of resource relations, where relations between stakeholders are divided into asymmetric and equivalent [2, 24]; network model, which is used to analyze relations and classify the stakeholders [25], allows to identify the behavior of individual stakeholders and to determine the behavior of the government in general, peculiarities of positions in the community and the properties of the network as a whole; Mendelow model, which allows to identify and classify the interested parties by such indicators as interest, i.e. desire to influence and power, i.e. the ability to influence, which is reflected in a twodimensional coordinate system [24]; the model depicts an assessment of the power of influence of the interested parties and interaction between the interested parties through the Freeman's power [1, 24]; the stakeholder circle [26], which represents a project surrounded by the project stakeholders; the performance prism focused only on major classes of project stakeholders [26].

In order to take into account the peculiarities of the stakeholders of agrarian projects, the author developed a conceptual model of mental space of the stakeholders of agro-industrial complex projects and anti-risk management of stakeholders of agro-industrial complex projects [27, 28, 29], as well as mathematical model of anti-risk management of stakeholders of agro-industrial complex projects [27, 30].

Despite the fact that some of the critical risks for agrarian projects are the risks associated with the projects concerned $[31,32]$, there is a need to develop tools for the anti-risk management of agrarian projects, which would take into account the specifics of such projects

The aim of this study is development of tools for risk management of agricultural projects.

Materials and methods. The methodological basis of the study is the general scientific principles of research, the fundamental provisions of the system approach, project management methodology and the process approach.

Results. In project management, the criterion for successful completion of the project is not always its deadline. There may be cases where it is necessary to complete the project with a limited amount of manpower, but not necessarily quickly. Sometimes the main criterion for project completion is not the shortest term and lowest cost, but the minimum risk $[31,34]$. In such situations on the network model it is necessary to define all complete paths and then choose one "critical" (by time, costs, risk or other criteria).

The author in the work [35] presented a method for determining all the complete paths of the network schedule of agro-industrial projects, which allows to determine all the complete paths of the network schedule of the project for the subsequent selection of optimal path by the necessary criteria. This method is an integral part of the proposed method of anti-risk management of agro-industrial complex projects on the basis of the critical path. The scheme of the method of anti-risk management of agro-industrial complex projects based on the critical path is shown in Fig. 1.

The method of anti-risk management of agro-industrial complex projects based on the critical path consists of the following steps, namely:

1. Filling the project risk management information base. At this stage, the project team generates a list of risks of agro-industrial complex projects that have been implemented previously, and enters information on risk management into the database. The project risk management plan is developed, where the general approaches to risk management, 
classification, identification of risks and the mechanism of response to the project risks are specified.

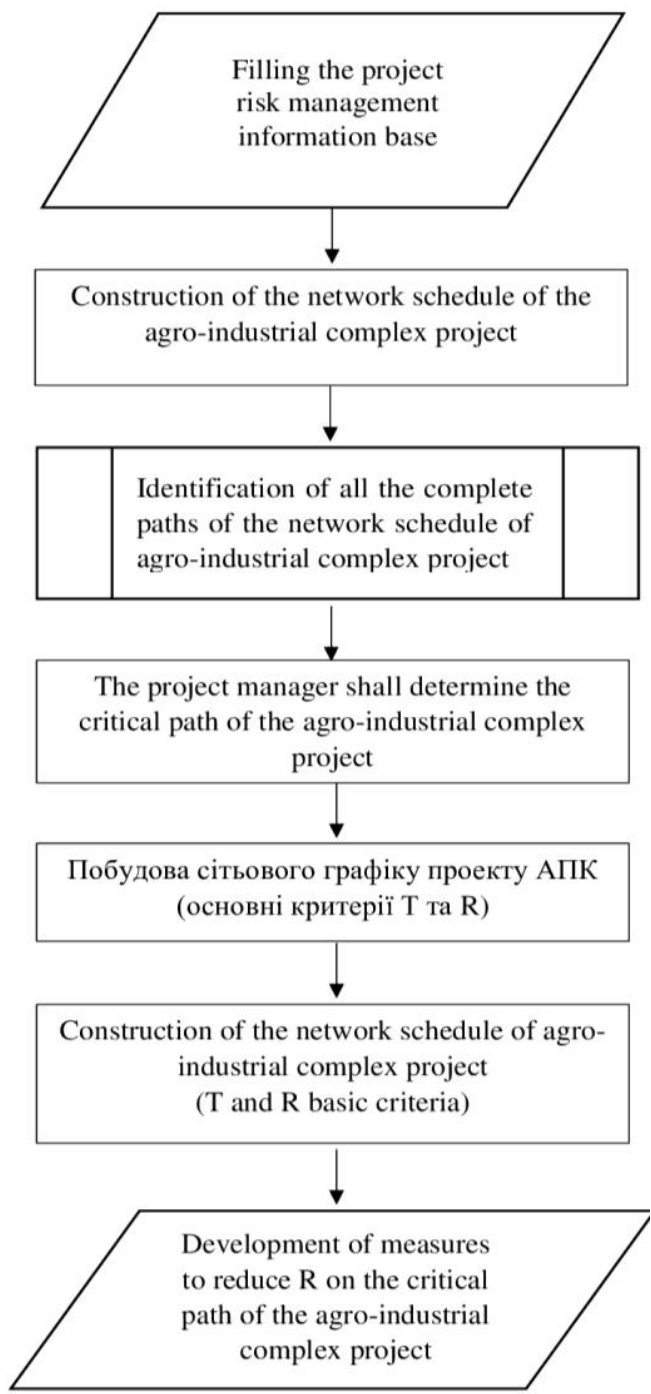

Fig. 1. The method of anti-risk management of agro-industrial complex projects based on the critical path
2. Construction of the network schedule of the agroindustrial complex project. The project team builds the network schedule of the agro-industrial complex project, which is a network model with pre-calculated parameters, which have temporal character. The basis in development of network schedule of the project is the work, for which it is necessary to take into account the availability of necessary resources, the event, i.e. the fact that all the works that are necessary for the next works are finished.

3. Identification of all the complete paths of the network schedule of agro-industrial complex project. At this stage, the project team determines all the paths from the initial to the final event, which are called full paths. To do this, it is proposed to use the method of determining all the full paths of the network schedule of agro-industrial complex projects, the detailed algorithm of which is given in the work [35].

4. The project manager shall determine the critical path of the agro-industrial complex project. The project manager determines the full path, which is the longest in duration from all the full paths. To do this, the duration of each work and event of the agro-industrial complex project shall be determined in advance.

5. Construction of the network schedule of agro-industrial complex project ( $\mathrm{T}$ and $\mathrm{R}$ basic criteria). The project team builds the network schedule of agro-industrial complex project taking into account not only the duration of works from the initial to the final event on the critical path, but also the value of project risk.

6. Development of measures to reduce $\mathrm{R}$ on the critical path of the agro-industrial complex project. At this stage, the project team develops strategies to prevent and avoid project risks.

As a result of the work we have the developed network schedule, determined critical path on the criteria of time and risk.

Conclusions. The method of anti-risk management of agro-industrial complex projects based on the critical path was developed, which allows to build a network schedule of the project not only take into account the duration of works on the critical path, but also the risk of the project, as well as to develop measures to reduce the value of risk on the critical path of the projects of agro-industrial complex.

\section{REFERENCES}

1. Freeman, R. E. (1984). Strategic Management: A Stakeholder Approach. Boston, MA: Pitman Publishing, 276.

2. Petrov, M. A. (2004). Stakeholder Theory: Practical Applications. Saint Petersburg University Bulletin. 8, 16, 51-68.

3. Donaldson, T., Preston, L. E. (1995). The stakeholder theory of the corporation: concepts, evidence, and implications. Academy of Management Review. 20, 1, 65-91.

4. Cleland, D. I., Ireland, L. R. (2002). Project Management: Strategic Design and Implementation. McGraw-Hill, London, 523.

5. Sisodia, R., Wolfe, D., Sheth, J. N. (2007). Firms of Endearment: How World-Class Companies Profit from Passion and Purpose. FT Press, 320.

6. Mitchell, R., Agle, B., Wood, D. (1997) Toward a theory of stakeholder identification and salience: defining the principle of who and what really counts. Academy of Management Review. 22 (4), 853-887.

7. Bourne, L., Walker, D. (2005). Visualizing and mapping stakeholder influence. Management Decision. 43, 5, 649-660.

8. Mouritsen, J., Thrane, S. (2006). Accounting, network complementarities and the development of inter-organisational relations. Accounting, Organizations and Society. 31, 3, 241-275.
9. Scott-Young, C., Samson, D. (2008). Project success and project team management: evidence from capital projects in the process industries. Journal of Operations Management. 26, 6, 749-766.

10. Abdullah, W., Maimun, W., Ramly, A. (2006). Does successful project management equates to project success. Proceeding of the International Conference of Cognitive Informatics 2006, 17-19 Jul, Beijing. China.

11. Yang J., Shen Q., Ho, M. (2007). An overview of previous studies in stakeholder management and its implications for the construction industry. Journal of Facilities Management. 7, 2, 159175.

12. Olander, S., Landin, A. (2005). Evaluation of stakeholder influence in the implementation of construction projects. International Journal of Project Management. 23, 4, 321-328.

13. Verenich, O. V. (2018). Management of mental space of projects and programs: the dissertation of the doctor of technical sciences: 05.13.22. Kyiv, 430.

14. Harris, F. (2010). A historical overview of stakeholder management. Construction Stakeholder Management. Blackwell Publishing Ltd., UK. 41-55.

15. Karlsen, J.T. (2002). Project stakeholder management. Engineer- 
ing Management Journal. 14, 4, 19-24.

16. Husieva, Yu.Yu. (2021). Methodology of stakeholder-oriented management of regional development projects and programs: the dissertation of the doctor of technical sciences: 05.13.22. Kharkiv, 306.

17. Cepeda Guaman, D. F. (2020). Risk management of stakeholders in organizational projects in the sphere of maintenance of aircrafts within the framework of the behavioral economy: the dissertation of the candidate of technical sciences: 05.13.22. Lviv, 182.

18. Bushuev, S. D., Bushueva, N. S., Zaharov, A. M. (2006). Models and methods of strategic development of fast-growing organizations. Project management and production development. 1(17), 5-13.

19. Kadykova, I. N., Larina, S. A., Chumachenko, I. V. (2016). Management of internal stakeholders of projects in the implementation of the program strategy. Management of Development of Complex Systems. 28, 68-74.

20. Oberemok, I. I. (2013). Ways for the development of corporate project management systems. Management of Development of Complex Systems. 15, 49-52.

21. A Guide to the Project Management Body of Knowledge (PMBOK® Guide) - Six Edition. (2017). USA : PMI, 574.

22. A Guidebook of Program \& Project Management for Enterprise Innovation. (2017). Japan : Project Management Association of Japan (PMAJ), 427.

23. IPMA I. C. B. IPMA Competence Baseline Version 3. (2006) The Netherlands: Nijkerk, 200.

24. ISO $21500: 2012$ Guidance on project management. [Electronic resource]. Access mode: https://www.iso.org/standard/50003.html.

25. Bilokon, A. I., Malanchii, S. O., Alkubalait, T. A. (2016). Theoretical aspects of identification and interaction of stakeholders in projects. Bulletin of the Dnieper State Academy of Civil Engineering and Architecture. 1 (214), 72-78.

26. Rowley, T. J. (1997). Moving beyond Dyadic Ties: A Network Theory of Stakeholder Influences. Academy of Management Re- view. 22(4), 887-910.

27. Martynenko, O. S. (2019). Methods for monitoring the requirements of projects and programs within resource constraints : the dissertation of the $\mathrm{PhD}$ of technical sciences: 05.13.22. Kharkiv, 193.

28. Krol, K. J. (2021). Anti-risk management tools of stakeholders in agro-industrial complex. The scientific heritage. 58, 58-62.

29. Krol, K. J., Denchyk, O. R. (2020). Model of mental space of stakeholders of agro-industrial complex projects. Proceeding of the 17th International Conference "Project management in the development of society". Topic "Project management in the digitalization of society", Kyiv, $206-209$.

30. Krol, K. J. (2020). Project management in the agro-industrial complex taking into account the interaction of the stakeholder mentality. Scientific notes of " $K R O K »$ University: a collection of scientific works. "Economy" series. 3 (59), 166-175.

31. Krol, K. J. (2020). Models of risk management of stakeholders in agro-industrial projects. Proceedings of the XVI International Scientific and Practical Conference "Project Management: Status and Prospects". 8-11 Sept. 2020, Mykolaiv, 61-63.

32. Krol, K. J. (2019). Stakeholders risk management in agroindustrial projects. Proceeding of the Scientific Works of the Cherkasy State Technological University. Series: Economic Sciences, Cherkassy, 55, 51-58.

33. Denchyk, O.R. Models and methods of integrated project risk management in agro-industrial complex : the dissertation of the $\mathrm{PhD}$ in Management: 073. Kyiv, 242.

34. Verenych, O.V. (2016). Development and implementation of a formalized model of the mental space of the project or program environment. East European Journal of Advanced Technology. 2, 3 (80), 21-31.

35. Krol, K. J. (2021). Tools of anti-risk project management of agro-industrial complex. Proceedings of the XVIII International Scientific Conference "Project management in the development of society". Topic "Project management in the context of the COVID-19 pandemic" 15 May., 2021, Kyiv. 189-193. 